\title{
EDUCATION AND TRAINING FOR THE FOURTH INDUSTRIAL REVOLUTION
}

\author{
Georg Spoettl ${ }^{1}$ and Vidmantas Tūtlys ${ }^{2}$ \\ ${ }^{1}$ University of Bremen, Bremen, Germany \\ ${ }^{2}$ Vytautas Magnus University, Institute of Education Science, Kaunas, Lithuania \\ E-mail: spoettl@uni-bremen.de
}

\begin{abstract}
Within the context of the 4th Industrial Revolution as an overall paradigm change, organization and work processes must switch together with automation following and real-time control. This applies to the contents of labor and to the interaction and connection between human and technology. Up to this point, there are only a few empirical studies about how digitized, decentralized and closely connected production system with "CyberPhysical-Systems" change the task and and competence profiles in the workplace. One outcome will be that intelligent workpieces will manage their way into production themselves. Depending on the implementation level of Industry 4.0 in companies, vocational education and training for the workforce is highly relevant and the vocational systems have to respond to the needs and expectations of the new technological challenges. Successful reactions of the vocational systems towards the 4th Industrial Revolution have to focus on curriculum development, teacher training and training of highly skilled workers. Approaches to fulfill these requirements will be discussed in this paper.
\end{abstract}

Keywords: education, fourth industrial revolution, training

\section{INTRODUCTION}

The $4^{\text {th }}$ Industrial Revolution involves technological advancement focused on technology combinations, including the Internet of Things, artificial intelligence, and cybernetic-physical systems. These advancements significantly affect the nature and interactivity of human labor, skills, and qualifications. The increasing prevalence of the 4th Industrial Revolution alters the requirements for skills, labor market mechanisms, and employment [1]-[3]. Digitalization, automation, and robotization are transforming the structure of work (digital Taylorism), negatively impacting both conventional routine works and highly skilled professions [1], [4]. The growth of the 4th Industrial Revolution drives the separation between the low-skill and high-skill workforce categories by decreasing job opportunities for the first category and dramatically increasing them for the second category, thus creating social dissatisfaction, insecurity, and tensions[1]. Research [5]on the impacts of Industry 4.0 for the metalworking and electronics manufactory in Germany revealed technical skills and qualifications of manufacturing workers and specialists will not reduce their significance and applicability.

There are proposed different scenarios of future development of technologies and work organization with rather contrasting views on the implications of the 4th Industrial Revolution for skills and jobs: starting from the elimination of the routine jobs and operations that are easily susceptible to algorythmization (including even highly skilled jobs) to the increasing complexity and enrichment of skilled and highly skilled jobs and related work processes with the new tasks and operations related to digitalization, increasing networking of work processes and informatization of work [6], [7]. The adaptations of qualifications to the requirements of Industry 4.0 are focused on the improvement of their responsiveness to the changes in the world of work. However, there is a lack of research and expert discussion on the implications of Industry 4.0 for professional qualifications and their systems. This paper seeks to fill in this gap and to initiate a more profound discussion about the change of 
vocational and professional qualifications created by the advent of the 4th Industrial revolution.

\section{A FRAMEWORK OF CHANGE OF QUALIFICATIONS IN THE CONTEXT OF INDUSTRY 4.0}

Industry 4.0 exerts some impact on qualifications outlined in different studies of development and literature[5]-[7]. Two main scenarios and their changes are discussed: (1) Changes of the content of work processes related to applied technologies, executed tasks, and work organization, etc., and (2) Macrostructural changes of work or work and labor market resulting into vanishing and emergence of occupations and professions.

The first type of change enhances new competence requirements and needs and fosters adjustments and updating of qualifications, whereas the second type of change mostly leads to emergence and extinction of qualifications. Both types of changes foster different shifts of the structure of qualifications, for example, increasing fragmentation of qualifications by seeking to increase the flexibility of their contents and adaptability to the requirements of fast adjustment or hybridization of qualifications caused by the merger of the different work processes due to technological development. These changes also influence the patterns and pathways of design, awarding and maintenance. They tend to require an increase of personalization and individualization of qualifications, a proliferation of corporate qualifications, enhance virtualization of the design, awarding and maintenance of qualifications.

\section{Character of Industry 4.0}

Meanwhile, industrialization has been going on for 250 years and is composed of a constantly evolving dynamic network of corporate-organizational and socio-institutional structures that have also ignited technological innovations[8]. This transition was followed by a thorough division of labor, a significant increase in productivity and a decrease in labor costs. The essence of work itself has changed during this period. In this sense, the central statement focuses on (1) the mechanization and automation of specialized manual labor and (2) the computerization of brain work (knowledge work) with the aid of algorithmic signal processing (digitalization) [8].

This method is assisted by the production technology, and above all by the automation process[9]. They reinforce the sense of the word digitalization or "4th Industrial Revolution" by highlighting that it is not adequate to solely talk about digitalization. Digitalization does not only include digital control of physical processes designed with human interfaces (as is the case with machine control tools such as $\mathrm{CNC}$ programs, free programmed control systems, driving regulations for drive systems). What's recent is the situation in which many digitally controlled processes connect horizontally and vertically with the internet through top-level data transmission (e.g. Internet of Things and Services[10]. In addition, those processes are assisted by the Artificial Intelligence frameworks, providing entirely new spaces for interaction between machines (e.g. multi-agent systems) and also between humans and machines. Examples include (1) linking of products and information (e.g. via RFID chips), (2) high velocity of information transfer (broadband), (3) unlimited storage options ("Cloud"/“Big Data"), (4) virtualization of equipment and products ("Cyber-Physical Systems"), (5) quick processing of a high wealth of information ("Real-Time processing, computer farms"), (6) objects communicating with each other ("Embedded Systems"), and (7) globally accessible data and services ("Smart Technologies").

Less technologically oriented dimensions

are (1) high-velocity innovation,

optimization and mastering of processes, (3) cooperation in heterogeneous teams, and (4) creativity during problem-solving processes. 
Therefore, there is more to be explored beyond digitalization as discussed in the technical context [9]. This development has been dubbed 'The Second Machine Era' and acatech - the German Academy of Science and Technology - [11] has been labeled the 'Fourth Industrial Revolution.' "Digitalization" mentioned in this article is interpreted to involve the influence of Artificial Intelligence, considering its social implications along with the Industry 4.0 context. It is intended to illustrate the distinctive features of this type of digitalization applicable to work in the manufacturing sector.

This idea of digitalization demonstrates the social importance of the developments, the evolving nature of interpersonal communication, man-machine-interaction and machine-machine-interaction with their major effect on the shaping of work, structure of work, economy, learning, requirements, and professions.

\section{Development Trends of Digitalization}

\section{The scope of digitalization}

Digitalization is a contradictory process. On the one hand, digitalization is a rationalization strategy with considerable risks for employment and working conditions. On the other hand, digitalization allows for the humanization of the world of work, prevents de-qualification and could contribute to demanding work that is supported by learning. However, it remains to be seen whether the use of technology and differentiated work organization in digitalized enterprises will pave the way for humanized work. This will depend on the orientation of the shaping of work and the availability of the required skilled workforce. In any case, vocational education and training is a key element for accessing the potential for a humane orientation of digitalization.

The development of a digital economy tends to increase the importance of appropriate competences as a key source of trust between producers, service providers and customers [12]. At the same time the digitalization of the economy and the advent of the 4th Industrial Revolution also potentially create important socio-economic dangers and risks that cannot be ignored when analyzing the implications of the change of required competence and development trends. For example, the kind of competences that are needed is strongly influenced by the particular work organization; e. g. changes brought about by the advent of Industry 4.0, especially the individualization and growing autonomy in the execution of work, as well as the fragmentation of many jobs into micro-jobs [12]. This has a deep impact on the socio-economic balance (see Figure 1) if it concentrates on one of the three pillars of the model which is depicted in Figure 1.

Digital Taylorism based on standardization and subsequent digitalization of the execution of complex work processes and "highly skilled“ tasks increases the replaceability of the highly skilled workforce [4]. The autonomy of medium and even highly skilled employees is also being contested and challenged by the increasing digital control of the execution of work tasks [12], [13].

Schwab [1] suggests the effects of digitalization for employment and industries depend on the interplay between the disruptive impact as technology-enhanced disruption and automation replaces labor resources, thus pushing labor to pursue other areas of use for their skills and the capitalization impact of jobs created, industries and companies generated by new goods and services requirements. IT and other disruptive technology advances improve productivity by eliminating current workers rather than producing new products that need more labor to manufacture them. This advancement tends to result in employment growth in high-income knowledge-intensive and innovative occupations, as well as lowincome manual employment that cannot be easily automated [1].Simultaneously, there is a major decline in daily middle-income 
employment. It promotes a greater division of skills and profits [14]. In comparison, the role of skilled labor in managing complex production processes in increasingly digitalized production environments is growing. The increasing complexity of work tends to increase the significance of non-routine activities in highly automated production processes and requires to subjectivize the work procedures by holistic perception, to apply explorative and dialogical approaches, intuition, empathetic bearing [14]. This is supported by the findings of the baymevbm study in the German market [4], [15].

The 4th Industrial Revolution is also expected to challenge the stability of the structure and contents of competence. Competence will cease to be just defined by more or less stable capabilities within a profession or domain of expertise, but rather by the continuous evolvement of dynamically changing capabilities through acquiring new skills and approaches to acting in the changing variety of [1]. These issues raise the following questions: (1) What is the role and place of the human factor in future socio-economic development related to digitalization? (2) What kinds of competencies are needed to access and ensure decent work and employment under the conditions of digitalization?

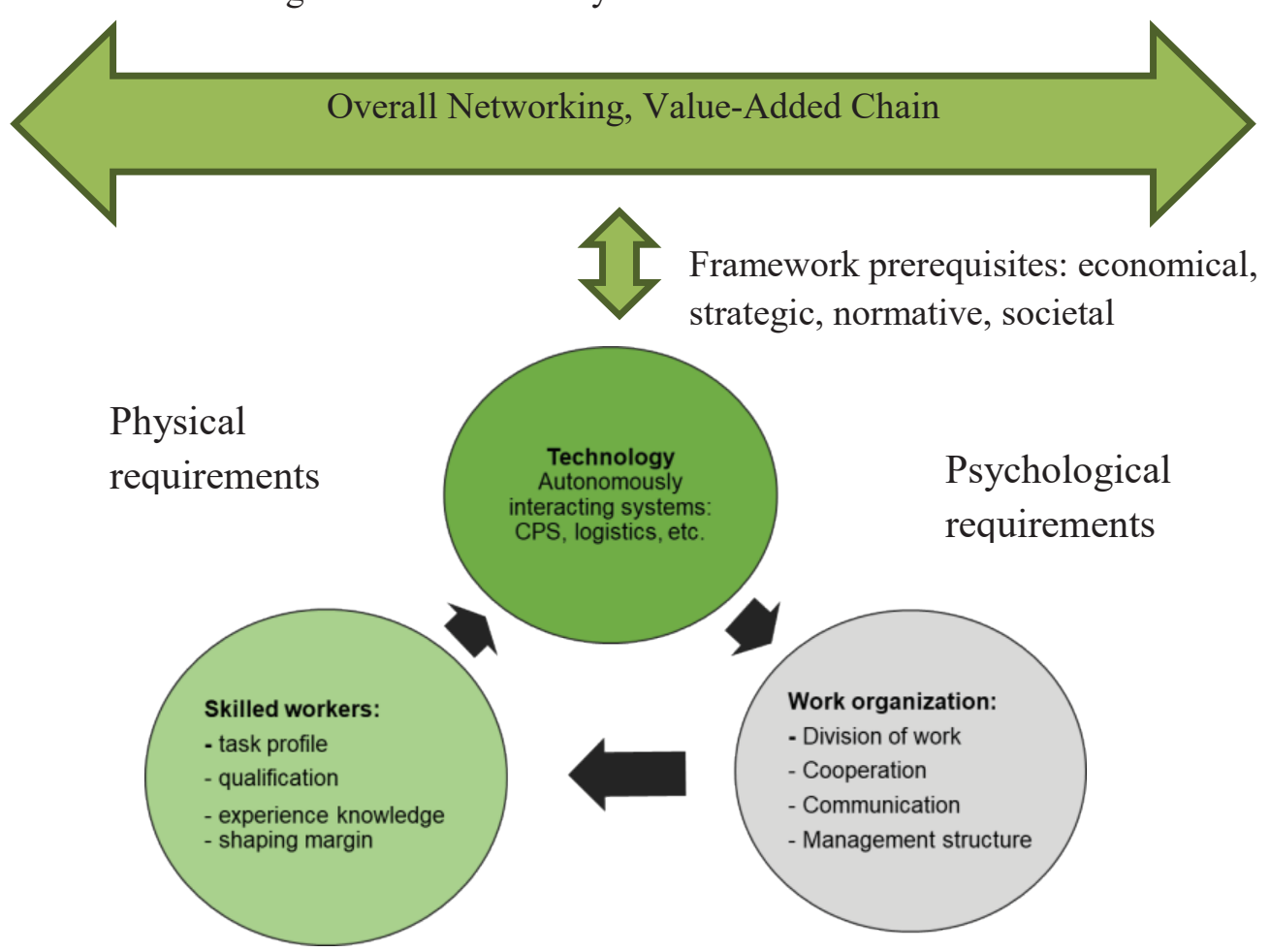

Figure 1. Socio-Technical Model [16]

\section{Technological view of development}

The 4th Industrial Revolution has been mainly described by the term DISRUPTION. It is presumed that due to the multifunctional abilities of technical facilities such as CyberPhysical Systems (CPS) as well as the supporting sensor-actuator technology and platform technologies, considerable changes will emerge in different economic sectors such as Industry, Handicraft, Health System, Education, and others. It is expected that these technological innovations will lead to a considerable optimization of work processes in companies.

CPS can determine and analyze the relevant dimensions of certain environments based on available global data and the action upon the physical world with the assistance of actors. Therefore, the aim is to use the 
technological means of micro-systems and information technology to create accessible and interconnected systems that use sensors to collect, analyze, interpret and make data accessible for internet-based services concerning particular circumstances in the physical environment.

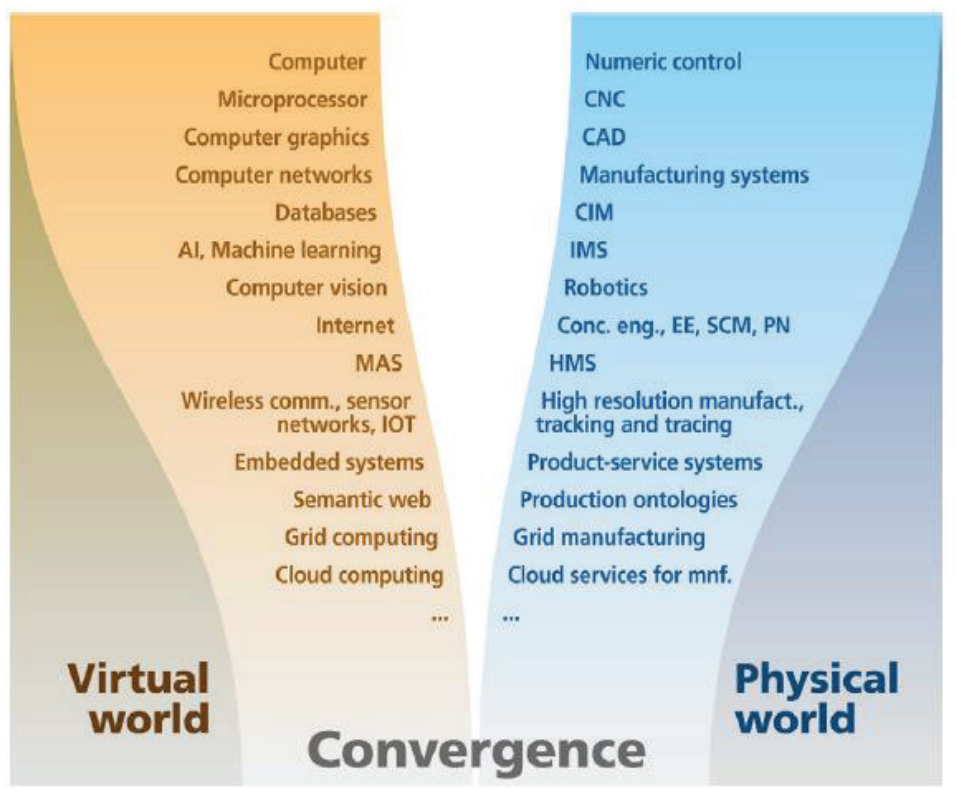

Figure 2. The Convergence of the Technology [17]
Industry 4.0 is among the application fields based on the Internet of Things [3], [18]. Objects in the physical environment are linked to the digital world [16], [19]. Therefore, Industry 4.0 can be considered as the firm formation of the Internet of Things through CPS. However, Industry 4.0 embraces a more systematic definition of interconnectivity that seeks to analyze and interrelate all phases of a process of creating values. The "interconnectivity intelligence" is supposed to cover the entire factory, whereby intelligent machines are required to coordinate the production processes on their own [9], even to the point of organizing the logistics. Human beings, therefore, hold the pivotal role within Industry 4.0 of controlling and managing the system. Industry 4.0 can reasonably be identified as a production paradigm as we have intelligent factories on the one hand, and
The interconnectivity in CPS between the physical and the virtual reality leads to new dynamic production processes that were previously not feasible. It can be considered as the integration of physical and virtual phenomena (see Figure 2).

\section{Physical}

production and logistics mechanisms on the other, which are interconnected globally through theinternet.This enables a flowof materials that can be optimized and interconnected to a degree so far unknown.In Germany, this development has been regarded as part of the fourth wave of industrializationwhich is commonly referred to as the "intelligent factory" or "smart factory".

This form of technological advancement must certainly be handled as a long-term strategic program aimed at creating intelligent closed processes in manufacturing and neighbouring fields as well as in the entire value-added production chain. It includes revolutionary concepts of man-machine interaction, to navigate future work-processes.

It is a question of top importance how education, training and further training should react to digitalization. From the perspective of 
technological development, digitalization and Industry 4.0 continue what has already played an important role in shaping the world of work and the structures of production since the implementation of computer technologies with first steps in the 1950s and 1960s. How to react to these developments has been a permanent issue for the development of training programs and it is likely to continue this way.

\section{The Digital Economy and Change in the Structure of Work}

Digital Taylorism based on standardization and subsequent digitalization of the execution of complex work processes and highly skilled tasks increases is replaceability of the highly skilled workforce [4]. The autonomy of medium and even highly-skilled employees is also being contested and challenged by the increasing digital control of the execution of work tasks [12], [13].

Answering the first question from the anthropological and ethical perspective leads to the assumption, that the human factor should constitute the basis of socio-economic development related to Industry 4.0 [20], as well as to the belief, that people and improvement of the quality of work and its accessibility for all [21].

Answering the second question, many authors suggest a holistic approach of competence that enables us to deal with the perspective of an unknown future. An interesting example of such an approach of competence is suggested by [22]. His competence model contains capabilities required for dealing with global openness and new perspectives, such as abilities to analyze and evaluate future-oriented developments, to promote interdisciplinary knowledge and to act in an interdisciplinary way by recognizing and assessing risks, dangers and uncertainties. With these and other elements "Competence 3.0" enables creative solutions to the unknown problems and constant optimization of the state of customers, commissioners, citizens, coworkers, students, etc. [22]. This second part of the answer guides us to long term perspectives and activities within TVET. Yet, even under a short term perspective answer are necessary about the requirements of the industry. Already today and in the near future, the question of which kinds of competencies are needed to develop is highly relevant.

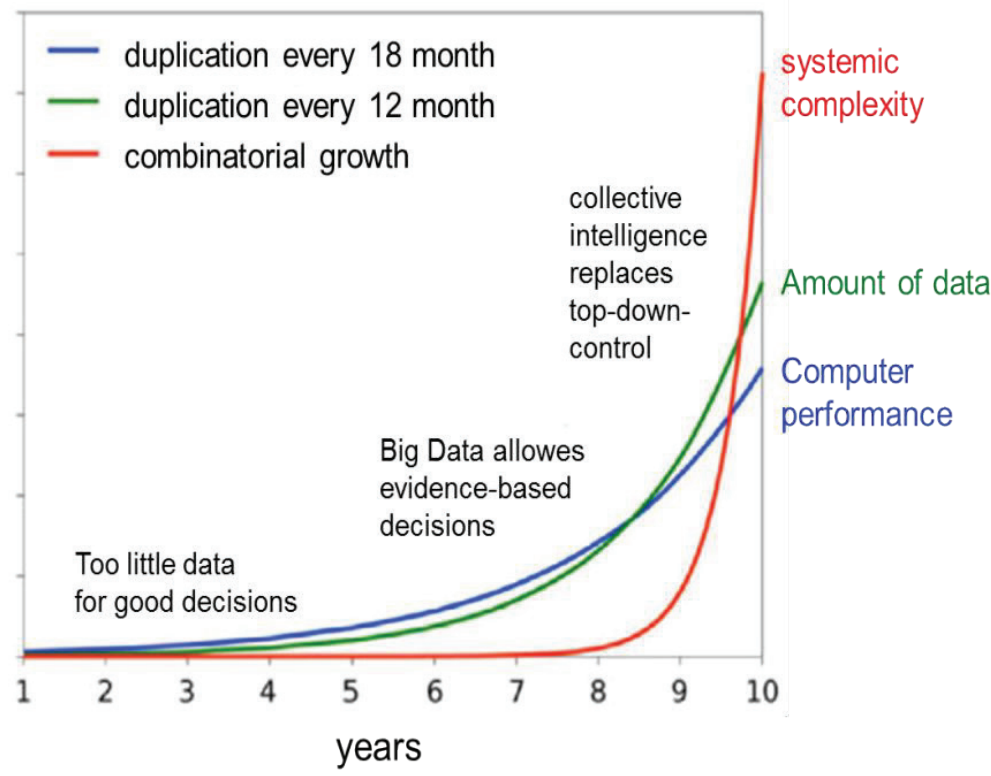

\begin{abstract}
Digital growth
The fast-paced networking of the world is explosively increasing the complexity of our societies. The traditional principle of top-down-control does no longer suffices. Approaches to shared control are getting more important. Adequate problem solving can only be safely guarded by collective intelligence.
\end{abstract}

Figure 3. "The Digital Manifest": Growth in Data Source: Spektrum der Wissenschaft, SonderausgabeDas Digitale Manifest, 2016 
Digitalization is seen as a paradigm shift whose primary objective is to implement Industry 4.0, networking and virtualization in all areas of the company. Thus, besides Industry 4.0, there is an intense industrial-political debate on the terms of Economy 4.0, Job 4.0 and Learning 4.0[23].

The discussions address the growth prospects of digitalization. Regardless of the problems that remain open about the consequences of Industry 4.0, IT-security, data protection, about significant industry shifts, concerning the effect of digitization on jobs, qualifications, the workplace, mobility, productivity, protection at work and so forth, innovations that promote Industry 4.0 are highly pursued by politics[24].

Research investigating the specifications of automation in the workplace focuses the "ironies of automation" that characterize employees' dilemmas in highly automated environments: workers participate in a controlling and monitoring role, but at the same time they have decreased chances of fully understanding ongoing processes due to growing automation.

This insight is necessary for gaining the essential experience for problem-solving [25]. All in all, it must be predicted that workers in many areas will continue to play a significant role in the manufacturing cycle. Questions which demand clarification in this respect are as follows: (1) How do the workers interact with the latest interrelated production environment, which can be expected to be smarter than the current settings according to all reports?, (2) What kind of transition will the qualifications and competency profiles undergo? And (3) Why does this occur? What are the most critical and controlling factors of influence for the design of networking processes?

This raises the issue of how far-separated production areas can be viewed as hybrid clusters of competence to control intelligent production processes, such as system building and information technology. Issues regarding training and the change of occupational requirements as they refer to initial and further training have only been in the focus of research since 2015. Anyhow, this can so far only be described as a careful approach to these questions which is most probably due to a lack of empirical studies. These revolutionary technological structures would have a major impact on the layout of production processes. The definition of complex and difficult "machining systems" into the digital and virtual operation of machine tools will transform work processes because automated machines can take over "dangerous," "very complex," "dreary" or "easily performed" operations. These innovations are not entirely new, but their introduction effects on the task profiles shift to allow them more or less demanding [26] as men and machines will work together across different interfaces. There is a trend that more and more portions of human activity are handled over by machines in the work processes and have a significant effect on the actions and critical thinking ability of the workers involved in this process. Decoding those innovations is crucial for vocational education.

\section{Changes of Work and Requirements}

Case studies in companies and expert interviews [5] summarize the challenges arising from the implementation of Industry 4.0. Skilled workers, master craftsmen, semiengineers, i.e. individuals with an occupational technical education and training and corresponding further training should be qualified for specializations applicable to Industry 4.0. They have to understand processes in their complexity and to secureperfect operation of plants. The skill in networked systems with decentralized intelligence, the ability to handle and evaluate data and the capacity to secure perfect plant operation are among the key essential criteria for work at production facilities. Other than this, it is required, of course that the existing conventional roles for skilled workers will still 
be coped with. The thus-far setting of main concerns on general questions of Industry 4.0 have to be expanded by technological priorities (CPS), by problem of work organization, by questions of work design, data security, programming techniques, troubleshooting and problem solving with the support systems and data analysis.

The technical networking applications and their associated CPS components are turning continuously to be prevalent. Therefore, along with the growing diffusion of Industry 4.0, plants and machines need to be planned and controlled beginning with (1) networking within heterogeneous facilities, (2) CP-systems and their general functioning, (3) the software and their embedding into processes.

Therefore the human-machine relationship is evolving significantly. It is indicated by the increased use of image processing, the transmission of information in different user appliances through visual processing, the use of videos and audiovisual language, etc.

In other words: context-related data that offers information about plants, manufacturing processes, and process operations are dominant. The action of the machines is monitored, analyzed and recorded with the assistance of integrated sensors and actuators. For the plant operator, the worker, the skilled worker, the data obtained are transformed into the information. The recorded data form again the basis for devices which, according to the situation, have to be employed by skilled personnel[5].

This is the issue of how Industry 4.0 can alter the organizational processes and thus the hierarchies in the companies. There are not many unambiguous studies available. So it remains unclear whether other decision-making processes on the skilled-worker-level can change.Is there still room for co-shaping by human beings in Industry 4.0 or will Industry 4.0 promote a "Taylorism 4.0"? The developers and drivers of the Industry 4.0 concept continue to emphasize that they strive for a cooperative relationship at all levels. Humans should be allowed to determine how their work is influenced by production. The working group Industry 4.0 comments: "The Smart Factory contains opportunity structures for a new work culture which is oriented towards the interests of the persons employed. Neither technology nor technical constraints should decide on the quality of work but scientists and managers who will shape and implement the Smart Factory. What is necessary for this situation is a perspective of socio-technological shaping within the organization of the work, further training, as well as technology and software frameworks with close mutual coordination. They should be "smooth" and concentrate on facilitating intelligent, cooperative, selforganized interaction through the entire valueadded chain between the workers and/or the technical operating systems [27].

\section{Changes on Skilled Worker Level}

Several studies with different goals have examined the development of "Industry 4.0" towards digitalization and its impact on the workforce. The results of the studies indicate that the current state of "Industry 4.0" implementation does not yet enable a reliable determination of the development of the need for skilled workers.

However, all findings conclude that employment opportunities for low-skilled employees will decrease along with the "Industry 4.0" implementation. It is expected that businesses will have a higher need for trained skilled workers and academically qualified personnel. However, the estimates only rarely collected in an empirically valid way.

Based on own surveys [5], the following tendential statements on the projected need for skilled workers can be summarized as follows[28]. 
RESPONSES OF THE VOCATIONAL EDUCATION SYSTEMS TO THE CHALLENGE

The technological and organizational changes of the 4th industrial revolution often require holistic and flexible answers from the qualification and education systems. These changes tend to merge and integrate different roles of employees, such as problem-solving, providing expertise, generation of ideas and solutions, development of products, services, and work processes, decision making. It fosters interdisciplinarity of the applied knowledge and skills and integration of the engineering professional competences (such as mechanics, electronics, mechatronics, networks, and software) with the advanced IT know-how and social competences. These developments can have different implications for the provision of education and training and qualifications. On the one hand, there is a variety of special training programs oriented to the solution of concrete problems and challenges related to the implementation and development of Industry 4.0 solutions that are provided by the leading technological companies. These training programs are often provided by using learning systems equipped with innovative industrial technologies or simulations of technological and work processes. Usually, such training courses are flexibly focused on the concrete aspects and competence requirements of Industry 4.0 in the process of production that creates a modular character of related curricula. Similarly customized basic and advanced training programs for the customers and users of the technological products and services are being developed. Such modular training programs permit to acquire the competencies needed to deal with particular issues of Industry 4.0 components, as well as to accumulate the sets of competencies needed for the management of the whole technological components and functions in the different workstations.
On the other hand, the development of Industry 4.0 requires holistic and open models of competence based on the systemic understanding of the work processes and their networking interrelations, as well as capabilities to combine real and virtual world information. Skills and competences of the process engineering become increasingly relevant and important for the execution of skilled workers in production.This is exemplified by the paradigm of augmented operators who are able to interact with intangible assets and digital content. These developments increase the demand for solid occupational based qualifications underpinned with the systemically provided knowledge and skills.

\section{CONCLUSION}

Modifying production systems that incorporate more cyber-physical structures must be assessed in the curricula for initial vocational education and further training. Within the context of the company's future growth, workers will thus contribute to long-term development processes and process optimization. This applies not only to occupations such as mechatronics, automation technology electronics technicians or industrial mechanics who currently work most often in maintenance divisions, but is also essential for other industrial occupations. All industries have to deal intensively with digitization issues to recognize the role of software and networking within Industry 4.0.

One of the key challenges is to improve and maintain access to skills and qualifications for all in the changing socio-economic situation, especially when the technological development tends to favor highly skilled people and thus dramatically increasing the risk of the Matthew effect. This situation presents the challenges both on the national level (to foster access of skills and qualifications in the national education systems and systems of qualifications) and on the international level 
to improve access to skills and qualifications in the global labor market by making national systems more open and accessible for "outsiders", especially for the citizens of developing countries. Making systems of vocational education and qualifications more inclusive and accessible not only increases the pool of a skilled workforce and the overall quality of human capital and skills (thus helping to satisfy increased and changed demand of skills in the world of work) but can also help to solve the risks and challenges of increasing skills polarization and Matthew effect under the conditions of Industry 4.0. The 1st and 2nd industrial revolutions made vocational skills and qualifications key factors of competition for and access to stable employment and revenues of skilled workers. Qualifications became important parts of the welfare systems that protected against the risk of work precariousness.

The 3rd industrial revolution made high skills and knowledge a key factor of competitiveness, career and socio-economic status starting to undermine the "social" role of qualifications, e.g., the shift from qualifications to competence in the practices of human resources management and development [4]. In the advent of the 4th industrial revolution, vocational and professional qualifications can lose their traditional power to protect against the risk of the precariousness of work due to the spread of automation, digitalization, digital Taylorism and other "technogenic" changes of work. At the same time, it can be expected that Industry 4.0 could exert an important influence on technologies for the organization of the systems of qualifications. This could change the regimes of access to qualifications. For example, usage of blockchain technologies in the assessment and recognition of competences and awarding of qualifications can lead to the fragmentation and individualization of information and data treatment in these processes, thus fostering their decentralization and dependence on the state institutions. Application of virtual and augmented reality for the development of vocational skills as replacement of work-based learning in real workplaces can increase the access of learners to work-based training and apprenticeship.

\section{REFERENCES}

[1] K. Schwab and World Economic Forum., The Fourth Industrial Revolution. UK: Penguin, 2016.

[2] C. Frey and A. Osborne, "The Future of Employment. How susceptible are Jobs to Computerisation?," 2013.

[3] G. Spöttl and L. Windelband, "Industrie 4.0 - Neugestaltung industrieller Prozesse und Konsequenzen für die Berufsausbildungin," in Spöttl $G$ and Windelband L eds,,Industrie 4.0 Risiken und Chancen für die Berufsbildung, Bielefeld: W. Bertelsmann Verlag, 2019, pp. 239-254.

[4] P. Brown, H. Lauder, and D. N. Ashton, The Global Auction. The Broken Promises of Education, Jobs, and Incomes. Oxford: Oxford University Press, 2011

[5] G. Spöttl, C. Gorldt, L. Windelband, T. Grantz, and T. Richter, Auswirkungen auf Aus- und Weiterbildung in der $M+E$ Industrie Studie herausgegeben von bayme vbm Die bayerischen Metall- und Elektro-Arbeitgeber. München: bayme vbm, 2016.

[6] H. Hirsch-Kreinsen and P. Itterman, "Drei Thesen zu Arbeit und Qualifikation in Industrie 4.0," in Spöttl $G$ and Windelband $L$ eds ,Industrie 4.0 - Risiken und Chancen für die Berufs bildung, Bielefeld: W. Bertelsmann Verlag, 2019, pp. 151-170.

[7] H. Lee and S. Pfeiffer, "- Szenarios zur Facharbeiterqualifizierung und ihrer be trieblichen Gestaltung," in Spöttl G and Windelband L eds ,Industrie 4.0 Risiken und Chancen für die Berufs bildung, Bielefeld: W. Bertelsmann Verlag, 2019, pp. 171-186.

[8] P. Brödner, Industrie 4.0 und Big Data Zwischen Hype und Horror auf dem Weg in eine bessere Welt. Bergkame: pad-Verlag, 2016.

[9] E. Brynjolfsson and A. McAfee, The second machine age: wie die nächste 
digitale Revolution unser aller Leben verändern wird. Kulmbach: Plassen Verlag ein Imprint der Börsenmedien AG, 2014.

[10] A. Bremer, Diffusion des Internet der Dinge auf die mittlere Beschäftigungsebene der Industrie Berufsbildung, Arbeit und Innovation Dissertationen und Habilitationen Band 45. Bielefeld: W. Bertelsmann, 2017.

[11] H. Kagermann, W. Wahlster, and J. Helbig, "Recommendations for Implementing the Strategic Initiative Industrie 4.0 Final report of the Industrie 4.0 Working Group," Frankfurt am Main, 2013.

[12] J. Tirole, Économie du bien commun. Paris: Presses Universitaires de France, 2016.

[13] R. Reich, "The Share-the-Scraps Economy,"2015.

https://robertreich.org/post/1098940950 95 (accessed Apr. 16, 2020).

[14] S. Pfeiffer, "Work 4.0 - New challenges for participation and qualification in Social Dimension and Participation in Vocational Education and Training," in Training Proceedings of the 2nd conference "Crossing Boundaries in VET, ”2017, pp. 30-34.

[15] G. Spöttl, "Development of Industry 4.0" - Are Skilled Workers and SemiEngineers the Losers," in 7th World Engineering Education Forum (WEEF), 2018

[16] H. Hirsch-Kreinsen, "The Power of the Practical Low Tech's Neglected Strength," Bus. Rev., vol. 18, no. 1, pp. 8-17, 2015.

[17] L. Monostori et al., "Cyber-physical Systems in Manufacturing," CIRP Ann., vol. 65, no. 2, pp. 621-641, 2016, doi: 10.1016/j.cirp.2016.06.005.

[18] L. Abicht and G. Spöttl, Qualifikationsentwicklungen durch das Internet der Dinge. Bielefeld: Bertelsmann W. Verlag, 2012.

[19] L. Windelband and G. Spöttl, "ManMachine-Interaction in the Field of Logistics: Example 'Internet of
Things," in Third International Conference LDIC Bremen February/ March 2012 , 2013, pp. 545-556, doi: 10.1007/978-3-642-35966-8 46.

[20] P. Destatte, "A propos de quelques révolutions industrielles [concerning some industrial revolutions]," 2016. https://phd2050.wordpress.com/2016/08 /16/ri-3de3/ (accessed Apr. 16, 2020).

[21] L. Bruni, "Il lavoro di domani sarà bello,"2017.

https://www.avvenire.it/opinioni/pagine/ il-lavoro-di-domani-sar-bello (accessed Apr. 16, 2020).

[22] M. Mulder, "Competence Theory and Research: A Synthesis," in In Competence -Based Vocational and Professional Education, vol. 23, Springer Nature, 2017, pp. 1071-1106.

[23] L. Schröde and H. Urban, Gute Arbeit Digitale Arbeitswelt - Trends und Anforderungen. Frankfurt am Main: Bund-Verlag, 2016.

[24] E. Hartmann, "Arbeitsgestaltung für Industrie 4.0: Alte Wahrheiten, neue Herausforderungen," in Zukunft der Arbeit in Industrie 4.0, Berlin: BMWi, 2014, pp. 7-13.

[25] L. Bainbridge, "Ironies of Automation," Automatica, vol. 6, pp. 775-779, 1983.

[26] M. Hartmann, "Methoden der Analyse beruflicher Handlungsprozesse und der Planung beruflicher Kompetenzentwicklung vor dem Hintergrund von Industrie 4.0 hrsg. von der Gesellschaft für Arbeitswissenschaft e.V. (GfA): Arbeitswissenschaft mit Interdisziplinarität und Metho," in Herbstkonferenz der GfA, Dortmund: GfA-Press 2015, 2015, pp. 1-14.

[27] H. Kagermann, W. Wahlster, and J. Helbig, "Umsetzungsempfehlungen für das Zukunftsprojekt Industrie 4.0. Abschlussbericht des Arbeitskreises Industrie 4.0," Frankfurt am Main, 2013.

[28] D. Autor, "Why Are There Still So Many Jobs? The History and Future of Workplace Automation," J. Econ. Perspect., vol. 28, no. 3, pp. 3-30, 2015. 